\title{
Pragmatic Encroachment and Political Ignorance
}

\author{
Forthcoming in The Routledge Handbook of Political Epistemology
}

\begin{abstract}
Take pragmatic encroachment to be the view that whether one knows that $p$ is determined at least in part by the practical consequences surrounding the truth of $p$. This view represents a significant departure from the purist orthodoxy, which holds that only truth-relevant factors determine whether one knows. In this chapter I consider some consequences of accepting pragmatic encroachment when applied to problems of political knowledge and political ignorance: first, that there will be cases in which it will not be practically rational to acquire political knowledge when the stakes surrounding one's political actions are high; second, that political knowledge can be more easily acquired when one values the welfare of others less; and third, that pragmatic encroachment may fail to account for a form of epistemic injustice when it comes to evaluating the political knowledge of members of marginalized groups. I argue that while these consequences are undesirable, the extent to which the pragmatic encroacher is committed to them depends both on the details of the theory, as well as the extent to which one considers political knowledge to be important.
\end{abstract}




\section{Pragmatic Encroachment}

Pragmatic encroachment is the view that whether one knows a proposition is, at least in part, a function of the practical factors that surround the truth or falsity of that proposition ${ }^{1}$. The kinds of practical factors that are discussed most often are the stakes in being right or wrong such that, paradigmatically, the higher the stakes surrounding the truth of $p$, the more difficult it is to know that $p^{2}$. Three main types of support have been put forth for the view: appeals to intuitive cases, empirical studies, and an argument that relies on a principled connection between knowledge and action.

The first kind of support involves appealing to cases in which it seems that one's willingness to ascribe knowledge varies with the relevant stakes. For example, say that you want to get to Spadina Avenue in order to check out a new ramen restaurant. While you have been to Spadina Avenue several times before, you are not an infallible city navigator; regardless, with very little at stake we may be happy to say that you know where Spadina Avenue is on the basis of your experience and memory. Consider now instead that getting to Spadina Avenue is a matter of life or death: the only pharmacy that carries your life-saving medicine is on that street, and it is closing soon. We then might have the following intuition: while your memory and experience are good enough to allow you to know where Spadina Avenue is when you are looking for a restaurant, it is not good enough when you are trying to get to the pharmacy. Given that you have the same memories and experiences in both cases, the argument goes, what stands in the way of your knowing are the high stakes. This is not to say that you could not come to know where the pharmacy is; indeed, you could come to know this after asking your friend who has been there many times for directions, or by using an app on your phone to plan a route, etc. The point is not 
that high stakes make knowledge impossible, but rather that when the stakes are high, the standards for acquiring knowledge can become more demanding.

While cases like these are ubiquitous in the pragmatic encroachment literature, they will do little to convince those who do not share the relevant intuitions. Some have thus appealed to empirical studies that investigate whether non-philosophers evaluate cases like the above in the same way as the pragmatic encroacher, or whether pragmatic encroachment can best explain certain patterns of knowledge ascriptions. Thus far, however, the results are inconclusive. While some studies have reported that the intuitions elicited by pragmatic encroachers are shared by non-philosophers (Sripada and Stanley 2012), others have failed to corroborate these results (Feltz and Zarpentine 2010; May et al. 2010; Schaffer and Knobe 2012; Buckwalter and Schaffer 2015; Rose et al. 2019). Other types of experiments are perhaps more promising. For instance, Pinillos (2012) conducted "evidence-seeking experiments" in which subjects were asked how much evidence one thought someone would need in order to count as knowing when the stakes varied (see also Francis et al. 2019), and Dinges and Zakkou's (2020) study looked at patterns of retractions of knowledge attributions, providing results that support the view that such patterns shift when certain practical factors shift. While these new approaches provide support for pragmatic encroachment, it is still up for debate how best to interpret the various kinds of empirical results (see for discussion Buckwalter and Schaffer 2015; Boyd 2016; Weatherson 2017).

The third and perhaps strongest form of support for pragmatic encroachment is a conceptual argument that relies on a principled relationship between knowledge and action. Say that knowledge is the norm of practical reason, such that if one knows that $p$ then it is rational to act as if $p$. It then follows that since practical factors determine whether it is rational to act, so too 
can they determine whether one knows. Again, consider the case of needing to get to Spadina Avenue when the stakes are high: since in this case it is not rational to act solely on the basis of what one remembers, then given the relationship between knowledge and action, neither will it be the case that one knows on that basis ${ }^{3}$.

Pragmatic encroachment is thus appealing in that it can explain a range of intuitive cases, and is closely tied to what many see as a plausible relationship between knowledge and action. What has yet to be explored, however, are the consequences of applying the view to issues of political knowledge and ignorance. Before doing this, however, we need to get a sense of what some of these issues are.

\section{Political Knowledge and Political Ignorance}

What constitutes political knowledge? Boudreau and Lupia (2011) argue that,

A common analytic definition of political knowledge is that it is a measure of a citizen's ability to provide correct answers to a specific set of fact-based questions. Typical political knowledge questions include "What is the political office held by [name of current vice president, British prime minister, or chief justice of the United States]" and "Which party has the most seats in the U.S. House of Representatives?" (p. 171)

This definition is that which is often employed in empirical studies of the level of political ignorance of a populace (Barabas et al. 2014; Bischof and Senninger 2017). More broadly, though, we can define political knowledge not in terms of any specific content, but instead in terms of the role that knowledge plays in political actions. For instance, Cameron Boult (forthcoming) 
characterizes political knowledge as involving "any belief that is of direct relevance to decision making on political issues" including issues like "whether to increase the national deficit, foreign aid, or to have public heath care" (p. 5). On this broader definition, while any proposition may be the object of political knowledge, whether it constitutes such knowledge will depend on the relevant context in which that knowledge is employed. While more can be said to make this notion more precise, I will here accept this broader conception.

Many have argued that political knowledge is important for a well-functioning democracy. For instance, De Vreese and Boomgaarden (2006) argue that,

Public knowledge of and participation in politics are at the core of democratic processes. The quality of citizenship and the health of the collective are preconditioned by political knowledge and there is a positive relationship between knowledge and the act of voting. (p. 317)

At the same time, it has been widely recognized that people are, by and large, politically ignorant (see Brennan (2016) and Somin (2016) for summaries of recent data). Given that an individual is likely to be politically ignorant, a question then becomes under what conditions it is practically rational ${ }^{4}$ for them to make the effort to acquire the political knowledge they lack, given that doing so comes at a practical cost. One argument for rational political ignorance concludes that it will often not, in fact, be worth it. Consider the case of voting in a large democracy: given that an individual vote is very unlikely to make a difference to the outcome, then even if it is the case that political knowledge allows one to make better voting decisions, it may not be worthwhile for one to acquire it for the purposes of voting, as the costs outweigh the expected benefits. 
There are, however, reasons to be worried about rationalizing political ignorance. As llya Somin (2006) argues,

The theory of rational ignorance implies not only that voters will acquire little or no political knowledge, but also that they will make little effort to use the knowledge they do have in a consistent and effective manner. It is not just that they might be apathetic; far worse, they sometimes use their knowledge in a way that increases the danger of making serious errors. (p. 256)

Somin argues that one problem surrounding political ignorance is that there will be a gap between the practical rationality of voting and that of reducing one's political ignorance. To show this, Somin first appeals to Derek Parfit's (1984) argument that it can be rational for one to vote in a large democratic system "so long as the voter perceives a significant difference between candidates and cares even slightly about the welfare of fellow citizens, as well as [their] own" (Somin 2010, p. 205). Somin defends this view via an expected utility calculation:

$$
D^{*}(300 \text { million } / 1000) /(100 \text { million })-C_{v}=U_{v}
$$

Where $U_{v}$ is the expected utility of voting, $C_{v}$ the practical cost of voting, and $D$ the expected difference in welfare per person if the voter's preferred candidate defeats their opponent, along with the assumption that one is participating in a system with 300 million voters, that one's ballot has a 1/100 million chance of being decisive, and that the voter values the welfare of their fellow citizens 1000 times less than their own. Somin argues that on plausible values of these variables (i.e. given that one does, in fact, value the welfare of one's fellow citizens at least a bit, that the difference in welfare that would result from electing different candidates is non-trivial, and that 
the practical cost of voting is not too high) it will, in fact, turn out to be rational for one to vote (i.e. it will be the case that $U_{v}>0$ ).

Somin's concern, however, is that it is much less likely to be practically rational to acquire political knowledge. To see why, he presents a similar calculation:

$$
D^{*}(300 \text { million } / 1000) /(100 \text { million })-C_{p i}=U_{p i}
$$

Where $U_{p i}$ is the expected utility of acquiring enough information to make the "right" decision when voting, and $\mathrm{C}_{\mathrm{pi}}$ is the practical cost of reducing one's political ignorance. The problem, Somin argues, is that the practical costs of acquiring political knowledge can be higher than the costs of voting ${ }^{5}$. As such, on plausible values of the relevant variables, it will often turn out that it is not practically rational to reduce one's political ignorance (i.e. it is likely that $U_{p i}<0$ ). Somin ultimately argues that given that widespread political ignorance is a problem, we then need to better incentivize individuals to take measures to reduce said ignorance. How we might do this is a matter of ongoing debate ${ }^{6}$.

We now have a general overview of pragmatic encroachment, as well as some problems surrounding political knowledge and ignorance. Next, I consider some consequences of accepting pragmatic encroachment when thinking about these problems.

\section{Three Consequences of Pragmatic Encroachment}

In this section I consider three consequences of pragmatic encroachment when it comes to issues of political knowledge and ignorance. These consequences centre on a general consequence of pragmatic encroachment, namely that as the standards for knowledge become more demanding, 
so too do the practical costs of acquiring it. Thus, given that the paradigmatic case of pragmatic encroachment is one in which high stakes increases the demands on knowledge, so too will they increase the cost of acquiring political knowledge ${ }^{7}$.

Consider an example. Say that I am trying to decide what to order at a restaurant, and that I have a terrible peanut allergy ${ }^{8}$. Despite the menu stating that a dish does not contain peanuts, if we accept pragmatic encroachment then I may not know that the dish does not contain peanuts on the basis of the available evidence, given that the stakes are high. In order to acquire this knowledge, then, I need to do some extra work, perhaps by acquiring additional evidence: I could, for example, ask a waiter to verify, or check with the chef, or run a detailed chemical analysis of the dish, etc. While acquiring this additional evidence may then put me in a position to know, it also comes at a practical cost. A consequence of accepting pragmatic encroachment, then, is that an increase in stakes leads not only to increased epistemic demands on acquiring knowledge, but also increased practical costs in acquiring that knowledge.

Of course, how significant these costs are will vary depending on how much work one needs to do in order to meet the standards required for good decision-making (e.g. checking with the chef is a small cost, running a scientific analysis looking for peanut traces is a large one). Regardless, given that increased standards for knowledge bring along increased costs in acquiring it, pragmatic encroachment has three consequences for thinking about political knowledge and ignorance: first, that political ignorance can become more practically rational as the stakes surrounding one's political actions go up; second, that one can acquire political knowledge by valuing the welfare of others less; and third, that pragmatic encroachment may warrant the 
epistemically unjust treatment of members of marginalized groups. I address these consequences in turn.

\subsection{Rationalizing (Even More) Political Ignorance}

The first consequence of accepting pragmatic encroachment is that doing so can widen the gap between the practical rationality of political action and that of acquiring political knowledge. To see why, we need to get a sense of which factors determine the stakes when it comes to political actions. Consider again the above calculation of the expected utility of voting: here we see that the greater the expected difference in welfare and the higher the chances of one's vote being impactful, the more rational it will be to vote, given that the cost of voting remains constant (e.g. it will take just as long to wait in line and cast a vote regardless of any other factors). However, these factors also determine, at least in part, the stakes involved in voting. For example, an election will be higher stakes if candidates have radically different policies with very different expected outcomes in terms of welfare for oneself and those one cares about, and lower stakes if the candidates have very similar policies, or have policies that have little impact on oneself and those one cares about. Thus, as the values of expected difference in welfare, concern for the welfare of others, and chance of one's actions making a significant impact go up, so too (ceteris paribus) do the stakes 9 .

The result is that accepting pragmatic encroachment also means accepting that there can be a larger gap between the practical utility of participating in a political process and that of acquiring political knowledge. For instance, say that you are going to vote in an election, the results of which will have significant practical importance to you. As the cost of voting is the same regardless of the stakes, it will become more rational to vote the more significant the practical consequences of 
that vote. However, on a pragmatic encroachment view, more significant political actions can present more significant obstacles to acquiring political knowledge: as it will be more difficult to know when the stakes are higher, one will be required to acquire more evidence in order to possess that knowledge, which brings along a higher practical cost. The consequence is that it may be more practically rational for one to refrain from acquiring political knowledge when it comes to voting in high-stakes elections ${ }^{10}$.

To illustrate this consequence a different way, consider an extension of the above restaurant case. Say that one has a peanut allergy, but is also extremely hungry; furthermore, given the high stakes, one is not in a position to know that one's dish does not contain peanuts solely on the basis of the menu description. If the demands for knowledge are high enough, it can be practically rational for one to order the dish - given that one needs to satiate one's hunger - despite it not being practically rational for one to do the work to acquire the relevant knowledge. The same, I argue, can be the case when it comes to voting in high-stakes elections: if the demands for knowledge are too high, it can remain practically rational for one to vote, despite it not being practically rational for one to acquire the relevant political knowledge.

Of course, this will not always be the case: if the expected difference in welfare is very high, then the increased expected benefits of acquiring political knowledge may swamp the associated costs. Nevertheless, there will still be cases in which the stakes surrounding one's political actions will be high, but in which it would be less practically rational to acquire political knowledge than if the stakes were lower. This consequence is undesirable insofar as it seems that possessing political knowledge is most important in high-stakes voting situations (although I consider a response to this in section 4). For example, while it may not be terribly important for one to possess political 
knowledge when it comes to an election in which there is only a marginal difference between the candidates, when these differences are significant it seems that it is much more important that voters possess political knowledge in order to make the best decisions. We thus get the conclusion that a pragmatic encroachment view of political knowledge may rationalize political ignorance when it comes to decisions regarding participation in important political processes.

\subsection{Selfishness as a Means to Acquiring Political Knowledge}

A consequence of pragmatic encroachment generally is that when practical factors stand in the way of knowing, one can acquire knowledge if those factors become less significant. For example, if the stakes surrounding the presence of peanuts in my dish prevent me from knowing whether there are peanuts in my dish, then one way I could acquire this knowledge would be if the stakes were lowered, e.g. if someone gave me an epi-pen. Critics of pragmatic encroachment have argued that the view thus warrants odd ways of acquiring knowledge, as well as a concept of knowledge that is unstable, given that practical factors can change in unexpected ways (see Russell and Doris 2008; Kim 2017).

Similar worries arise when considering political knowledge. For example, say that there are large potential differences in welfare for me given the results of an upcoming election, as one of the key issues pertains to increasing minimum wage, and I have very little money. Say also that I have collected some evidence with regards to the policies of the respective candidates, but, given that the stakes are high, I do not qualify as knowing which candidate is the right choice. One way that I could acquire political knowledge, then, would be if the stakes were to become lower as a result of my financial situation improving, e.g. if I get a new, well-paying job. It is prima facie odd, 
however, that my employment status can have a direct impact on how much political knowledge I possess.

There are additional ways that one can lower the stakes when it comes to one's political knowledge; specifically, by valuing the welfare of others less. For instance, Edlin et al. (2007) argue that voting is likely not practically rational for someone who has purely selfish motives, given that a reduction in the concern for the welfare of others will result in a reduction in the overall expected utility. In general, then, the more one values the welfare of others, the more rational it will be to vote; at the same time, an increased concern for others will also raise the stakes surrounding one's actions, thus making it more difficult and practically costly to acquire relevant political knowledge. Accepting pragmatic encroachment thus has the additional consequence that there is a seemingly implausible relationship between one's concern for the welfare of others and the rationality of acquiring political knowledge, such that if one values the welfare of others too much then it may no longer be practically rational for one to acquire that knowledge.

\subsection{Political Ignorance and Epistemic Injustice}

A final consequence of pragmatic encroachment is that it may warrant the epistemically unjust treatment of members of marginalized groups when it comes to ascriptions of political knowledge. For example, consider a member of a minority group who has to choose between two white men in an election: both have histories of policy decisions that tend not to be favorable towards minorities, although one may end up making slightly more favorable policy decisions than the other. In this case the stakes for the minority voter may be much higher than a white male voter. As we have seen, a consequence of pragmatic encroachment is that as a result of these higher 
stakes, the standards for knowing, and hence the practical costs of acquiring knowledge, will be higher for the minority voter.

While the pragmatic encroacher will not take issue with any of this, a concern with this consequence is that it may run afoul of what seem to be instances of epistemic injustice. For instance, Mikkel Gerken (2019) argues that a consequence of pragmatic encroachment in general is that it can warrant a form of discriminatory epistemic injustice, i.e. discrimination against others as knowers in virtue of paradigmatically unjust features ${ }^{11}$. Gerken provides an example in which one's financially dire circumstances can make the practical consequences surrounding the truth of some proposition more significant, which, according to the pragmatic encroacher, can prevent one from knowing it: pragmatic encroachment would thus warrant treating individuals in such circumstances as knowing less, given that they in fact do know less according to the theory. The worry, however, is that such treatment is not, in fact, warranted: if it is an injustice to treat such individuals as knowing less, then this is because they do, in fact, possess knowledge, but are being treated as if they do not.

When applied to the domain of political knowledge, then, pragmatic encroachment has the consequence not only of potentially failing to account for the epistemically unjust treatment of marginalized groups, but also of deeming it less practically rational for members of marginalized groups to acquire said knowledge, given that doing so will be costlier. Again, consider the above case where a member of a minority group needs to decide between which of two white male candidates she will vote for. Given that the stakes are higher for her than for someone who will not be affected nearly as much by the outcome, the demands of knowing which candidate is the better choice will be much higher, and hence it will also be much more practically costly for her to 
acquire that knowledge. Given the increased practical costs, however, it may be less practically rational for her to acquire that political knowledge. Pragmatic encroachment may then warrant an additional kind of injustice, one that deems it practically irrational for a member of a minority to acquire political knowledge.

In this section I have traced three consequences of applying pragmatic encroachment to problems of political knowledge and ignorance, all of which appear to run afoul of commitments one might have with regards to the value of political knowledge, appropriate means of acquiring political knowledge, and epistemic injustice. In the next and final section, I will consider a possible response on behalf of the pragmatic encroacher.

\section{Pragmatic Encroachment and the Value of Political Knowledge}

Does the pragmatic encroacher have any recourse for dealing with these worries? Possibly. Consider first that in discussing political knowledge and ignorance, I have assumed that there is an important connection between them, such that in reducing political ignorance one aims to acquire political knowledge. However, one might deny this, and thereby call into question whether there is any particular value in possessing political knowledge when it comes to making good political decisions. For instance, some have argued that individuals can make good political decisions solely on the basis of heuristics (such as party affiliation) and other kinds of information cues (i.e. "bits of information that enable people to make judgments and decisions about an attitude object without in-depth knowledge" (Bowler and Nicholson 2018, p. 382)), while others have argued that individual-level ignorance is not necessarily a barrier to good decision-making at the group level. For instance, Hélène Landemore (2013) argues for what she calls the "strong epistemic argument 
for democracy": despite there being widespread political ignorance at the level of individual members of a democratic society, decisions made in a democracy will typically be better than those made in other political systems, given the epistemic benefits of cognitive diversity (i.e. that in the right circumstances, due to differences in the ways that individuals interpret the world, mistakes in reasoning will systematically cancel each other out, resulting in overall better decisionmaking in the aggregate (p. 160)). If the aim of reducing political ignorance is to attempt to make good political decisions, either at the individual or societal level, then it may be the case that political knowledge is, strictly speaking, not very important in achieving this goal.

What the pragmatic encroacher might argue, then, is that even if political knowledge becomes more difficult to acquire as the stakes go up, the costs of reducing political ignorance may not, given that one does not need to meet the standards of political knowledge for one to contribute to a good decision-making at the societal level. This response may be available especially for a view of pragmatic encroachment in which it is only the standards for knowledge, but not one's epistemic position otherwise, that is affected by political considerations (see Fantl and McGrath 2009). Whether this response is enough to immunize the pragmatic encroacher against the three consequences I have presented here will depend both on how one interprets the details of pragmatic encroachment, as well as what one takes the relationship between political ignorance and knowledge to be. 
Works Cited

Anderson, C \& Hawthorne, J 2019, 'Knowledge, Practical Adequacy, and Stakes', in T. S. Gendler \& J. Hawthorne (eds.), Oxford studies in epistemology (Vol. 6), Oxford University Press, pp. 234-257.

Barabas, J, Jerit, J, Pollock, W \& Rainey, C 2014, 'The question (s) of political knowledge', American Political Science Review, vol. 108, no. 4, pp. 840-855.

Bischof, D \& Senninger, R 2018, 'Simple politics for the people? Complexity in campaign messages and political knowledge', European Journal of Political Research vol. 57 no.2, pp. 473-495.

Boudreau, C \& Lupia, A., 2011, 'Political knowledge', in Druckman, JN, Green, DP, Kuklinski, JH \& Lupia, A (eds.), Cambridge handbook of experimental political science, Cambridge University Press, pp. 171-183.

Boult, C Forthcoming, 'The (Virtue) Epistemology and Political Ignorance', American Philosophical Quarterly.

Bowler, S \& Nicholson, SP 2018, 'Information Cues and Rational Ignorance', in Congleton, R, Grofman, B \& Voigt, S (eds.), The Oxford Handbook of Public Choice, pp. 381-394.

Boyd, K 2016, 'Pragmatic Encroachment and Epistemically Responsible Action', Synthese vol. 193, no. 9, pp. 2721-2745 .

Brennan, J, 2016, Against Democracy, Princeton University Press, Princeton.

Brown, J. 2008, 'Subject-sensitive invariantism and the knowledge norm of practical reasoning', Nous no. 42, vol. 2, pp. 167-189. 
Buckwalter, W \& Schaffer, J 2015, 'Knowledge, stakes, and mistakes', Noûs vol. 49 no. 2, pp. 201234.

De Vreese, CH \& Boomgaarden, H 2006, ‘News, political knowledge and participation: The differential effects of news media exposure on political knowledge and participation', Acta Politica vol. 41 no. 4, pp. 317-341.

Dinges, A \& Zakkou, J 2020, 'Much at stake in knowledge', Mind \& Language, pp. 1- 21.

Edlin, A, Gelman, A \& Kaplan, N 2007, 'Voting as a Rational Choice: Why and How People Vote to Improve the Well-Being of Others', Rationality and Society no. 19, pp. 293-314.

Fantl, J \& McGrath, M 2009, Knowledge in an Uncertain World, Oxford University Press, Oxford.

Feltz, A \& Zarpentine, C 2010, 'Do you know more when it matters less?', Philosophical Psychology vol. 23 no. 5, pp. 683-706.

Francis, K, Beaman, P \& Hansen, N 2019, 'Stakes, scales, and skepticism', Ergo, pp. 427-487.

Fricker, M 2007, Epistemic injustice: Power and the ethics of knowing, Oxford University Press, Oxford

Ganson, D 2008, 'Evidentialism and pragmatic constraints on outright belief', Philosophical Studies vol. 139 no. 3 , pp. 441-458.

Gerken, M 2019, 'Pragmatic Encroachment and the Challenge from Epistemic Injustice', Philosophers' Imprint vol. 15, pp. 1-19.

Gerken, M 2017, On Folk Epistemology: How we think and talk about knowledge. Oxford University Press, Oxford. 
Hawthorne, J 2004, Knowledge and Lotteries, Oxford University Press, Oxford.

Kim, B 2017, 'Pragmatic encroachment in epistemology', Philosophy Compass vol. 12 no. 5, pp. 114.

May, J, Sinnott-Armstrong, W, Hull, J \& Zimmerman, A 2010, 'Practical interests, relevant alternatives, and knowledge attributions: An empirical study', Review of Philosophy and Psychology vol. 1, no. 2, pp. 265-273.

Nagel, J 2010, 'Knowledge ascriptions and the psychological consequences of thinking about error', The Philosophical Quarterly vol. 60 no. 239, pp. 286-306.

Page, B 2015, 'That Same Old Song: Somin on Political Ignorance', Critical Review vol. 27 no. 3-4, pp. 375-379.

Parfit, D 1984, Reasons and Persons, Clarendon Press, Oxford.

Pinillos, NA 2012, 'Knowledge, experiments and practical interests', in Brown, J \& Gerken, M (eds.), Knowledge ascriptions, Oxford University Press, Oxford, pp. 192-219.

Rose, D, Machery, E, Stich, S, Alai, M, Angelucci, A, Berniūnas, R, Buchtel, EE, Chatterjee, A, Cheon, H, Cho, IR \& Cohnitz, D 2019. 'Nothing at stake in knowledge', Noûs vol. 53 no.1, pp. 224-247.

Russell, GK \& Doris, J M 2008, 'Knowledge by Indifference', Australasian Journal of Philosophy vol. 86, pp. $429-37$.

Schaffer, J \& Knobe, J 2012, 'Contrastive knowledge surveyed”, Noûs vol. 46, no. 4, pp. 675-708.

Shin, J 2014, 'Time constraints and pragmatic encroachment on knowledge", Episteme vol. 11 no.

2, pp. 157-180. 
Somin, I 2016, Democracy and political ignorance: Why smaller government is smarter. Stanford University Press.

Somin, I 2010, 'Foot Voting, Political Ignorance, and Constitutional Design', Social Philosophy and Policy vol. 28, no. 1, pp. 202-227.

Sominm I 2003, 'Political ignorance and the countermajoritarian difficulty: A new perspective on the central obsession of constitutional theory', lowa Law Review vol. 89, pp. 1287-1372.

Sripada, CS \& Stanley, J 2012, 'Empirical tests of interest-relative invariantism', Episteme vol. 9, no. 1, pp. 3-26.

Stanley, J 2005, Knowledge and practical interests, Oxford University Press, Oxford.

Weatherson, B 2017, 'Interest-relative invariantism', in Jonathan Ichikawa (ed.), The Routledge Handbook of Epistemic Contextualism, Routledge.

Williamson, T 2005, 'Contextualism, subject-sensitive invariantism and knowledge of knowledge', The Philosophical Quarterly, vol. 55, no. 219, pp. 213-235.

\footnotetext{
${ }^{1}$ Here I will focus on the metaphysical thesis (i.e. one that pertains to the nature of knowledge), and will not have anything to say about a strictly semantic version of the view (i.e. one that pertains solely to the truth value of knowledge ascriptions).

${ }^{2}$ Other factors, such as time constraints with regards to forming a belief or acting, have also been proposed as a potentially relevant practical consideration (see Shin 2014). It is also up for debate as to whether practical factors affect knowledge directly, or only indirectly in virtue of affecting
} 
belief. For example, one might argue that one is simply less likely to believe that $p$ when the stakes surrounding $p$ are high, and thus may fail to know only in virtue of failing to believe (see Ganson 2008; Nagel 2010; Gerken 2017). Here I will take pragmatic encroachment to be the view that practical factors are relevant to knowledge regardless of their effects on belief.

${ }^{3}$ Versions of this argument can be found in Hawthorne (2004), Stanley (2005), Fantl and McGrath (2009), and elsewhere. They have, as one might suspect, also received their share of objections (see e.g. Williamson 2005; Brown 2008; Gerken 2017).

${ }^{4}$ There are, of course, other kinds of value that one might consider when determining whether one should acquire political knowledge, especially epistemic or moral value. Here, however, I will only be concerned with practical value associated with decision-making. However, depending on what one takes the relationship between stakes and standards for epistemic rationality to be, discussions of others kinds of value may be relevant, as well.

${ }^{5}$ How costly it is to acquire political knowledge will of course not be uniform for everyone. Indeed, there will be cases in which acquiring such knowledge will be easy and low cost, e.g. cases in which one can acquire some relevant political knowledge just by Googling. That being said, what is important for Somin's view is that there can be some political matters that require more effect to be known, say by requiring in-depth research, consulting experts, etc.

${ }^{6}$ Somin's own solutions focus on measures meant to provide individuals with more effective ways of participating in a political system, and by significantly reducing the size of government (see Somin 2010; see Page 2015 for criticism).

${ }^{7}$ I say this is the paradigmatic case as I leave it open that it is not necessarily the case that for every proposition and every practical consequence, high stakes increases the demands on knowledge (for instance, Anderson and Hawthorne (2019) argue that there can be cases in which 
higher stakes result in the standards for knowledge being less demanding). However, it is also the case that the pragmatic encroacher ought not be satisfied with a bare existential claim (i.e. merely that there is some proposition, in some possible circumstance, in which practical factors affect the demands of knowing it) lest they pull all the teeth from the theory.

${ }^{8}$ Cases like this are common throughout the literature; for an empirical study of similar cases, see Sripada and Stanley (2012).

${ }^{9}$ One might wonder whether in such a situation the stakes surrounding one's vote should be considered "high", given that one still has only a very small chance of making a difference in the outcome of the election. There are a few potential responses to this worry. First, given that the chance of making a difference is only one variable among many that determine what is at stake for someone, merely having a low chance of making a difference does not preclude a situation from being high stakes. Second, I am here making a comparative claim, i.e. that more significant differences in candidates make stakes higher, even though they may not be overall very high. Finally, there are additional consequences beyond the outcome of an election that can be taken into account when determining the stakes surrounding one's voting, for instance those pertaining to one's political interests.

${ }^{10}$ Again, consider the above equation for the utility of reducing political ignorance, i.e. $U_{p i}=$ $D^{*}(300$ million/1000)/(100 million $)-C_{p i}$. There can then be cases which $U_{p i}$ is positive, given that $D^{*}(300$ million $/ 1000) /(100$ million $)>C_{p i}$. A consequence of pragmatic encroachment is that as the left side increases, so too does the right side. However, there is no reason to think that the increases will be uniform. For instance, it can be the case that the costs of meeting the standards for knowledge according to pragmatic encroachment will swamp the expected difference in expected welfare, depending on how difficult it is to meet the increased epistemic standard. 
${ }^{11}$ These and related notions of epistemic injustice originate in Fricker (2007). 